\title{
Attitudes of Consumers from University of Novi Sad toward Advertising through Sport among the Question how often Consumers purchase Sporting Goods
}

\author{
Zoran Milosevic ${ }^{1}$, Dusko Bjelica ${ }^{2}$, Radenko Matic ${ }^{1}$ \\ 'University of Novi Sad, Faculti of Sporth and Physical Education, Novi Sad, Serbia, ${ }^{2}$ University of Montenegro, Faculty for Sport and Physical \\ Education, Niksic, Montenegro
}

\begin{abstract}
This research was aimed at gaining relevant knowledge about the attitudes of University of Novi Sad consumers toward advertising through sport among the question how often consumers purchase sporting goods. The sample included 168 students from Faculti of Sporth and Physical Education in Novi Sad, divided into six subsample groups: consumers who do not purchase sport goods at all, then consumers who purchase sport goods less than ones a month, next 1-3 a month, 4-6 a month, 7-9 a month, as well as consumers who purchase sport goods more than 10 times a month. The sample of variables contained the system of three general attitudes which were modelled by seven-point Likert scale. The results of the measuring were analyzed by multivariate analysis (MANOVA) and univariate analysis (ANOVA) and Post Hoc test. Based on the statistical analyses it was found that significant differences occur at multivariate level, as well as between all three variables at a significance level of $(p=.000)$. Hence, it is interesting to highlight that it was found there were significant differences showed up between the consumers who purchase sport goods. The significant differences were found in two of three variables, while the consumers who purchase sport goods less than 3 times a moths had much more negative attitudes toward advertising though sport.
\end{abstract}

Key words: Attitudes, Advertising, Sporting Goods, Novi Sad

\section{Uvod}

Vodeći se činjenicom da ulaganje u reklamiranje u sportu kao dijelu korporativne marketinške strategije neprestano raste, nastala je i potreba za istraživanjima u ovoj oblasti kako bi se utvrdile najbolje perspektive (Muratović, Bjelica, i Popović, 2014). Sistematsko proučavanje odnosa potrošača prema reklamiranju je ukorijenjeno u studiji Bauer-a i Greyser-a (Popović, 2011), dok je kapitalan doprinos nauci kada je reklamiranje u sportu u pitanju dao Pyun (Klačar i Popović, 2010), koji je sproveo istraživanje u kojem je konstruisao novi model za ispitivanje odnosa potrošača prema reklamiranju u sportu i time omogućio raznim istraživači- ma da ispituju stavove i uvjerenja potrošača prema reklamiranju u sportu širom svijeta i upoređuju svoje zaključke. U studijama koje su istraživale stavove prema opštem reklamiranju četrdesetih i pedesetih godina prošlog vijeka, prema Bauer-u i Greyser-u (Popović, Bjelica, Jakšić, \& Georgiev, 2013; Popovic, 2015; Popović, \& Milašinović, 2016), došlo se do zaključaka da potrošači, generalno imaju pozitivne stavove. Međutim, upoređujući navedene rezultate sa novijim istraživanjima (Bjelica, i Popović, 2011; Popović, 2011b; Popović, Molnar, i Radovanović, 2011a; Popović, Matić, Milašinović, Jakšić, \& Bjelica, 2015a; Popović, Matić, Milašinović, Hadžić, Milošević, \& Bjelica, 2015b; Popović, Matić,

\section{Correspondence:}

Montenecroro R. Matic

Sport University of Novi Sad, Faculti of Sporth and Physical Education, Lovcenska 16, 2100 Novi Sad, Serbia E-mail: radenkomatic@uns.ac.rs 
Milašinović, Vujović, Milošević, \& Bjelica, 2015c), utvrđeno je da potrošači imaju sve više negativne stavove prema reklamiranju. Nakon određenog vremena, Shavitt i saradnici (Bjelica i Popović, 2011) su utvrdili da ispitanici u njihovoj studiji imaju mnogo pozitivnije stavove prema reklamiranju nego što je to bio slučaj u prethodnim studijama. Pretpostavljalo se da stavovi variraju kod ispitanika, budući da oni razlikuju određene vrste reklamnih poruka, a Mittal (Popovic, 2011) je utvrdio da imaju mnogo negativnije stavove prema reklamiranju na televiziji u poređenju sa opštim reklamiranjem. Sa povećanjem negativnih stavova prema reklamiranju na televiziji marketari su morali osmisliti način kako da povrate povjerenje gledalaca kada je reklamiranje na televiziji u pitanju, a to su učinili na taj način što su počeli primjenjivati nove tehnološke izume kao što su video rekorderi koji su nezainteresovanim gledaocima za reklamne poruke omogućavali da preskoče djelove koji im nijesu bili interesantni (Bjelica, Popović, Jakšić, Hadžić, \& Akpinar, 2014b; Bjelica, \& Popović, 2015a; Bjelica, \& Popović, 2015b; Bjelica, Gardasevic, Vasiljevic, \& Popovic, 2016a; Bjelica, Gardašević, Vasiljević, \& Popović, 2016c). Uporedo sa navedenim izumom, stavovi prema reklamiranju u sportu su, ponovo postali mnogo pozitivniji. Međutim, ovaj izum nije omogućavao gledaocima da preskoče dio programa sa reklamnim porukama kada je praćenje sportskih događaja u pitanju, budući da su se oni odvijali u trenutku vremena. Ipak, bliskost i privrženost sportu i sportskim subjektima su, vremenom nadvladale negativne stavove gledalaca koje su oni imali kada je opšte reklamiranje u pitanju i dovele do toga da reklamiranje u sportu zauzme mjesto koje mu danas pripada. Samim tim se postavilo i pitanje, kako kupovina sportskih proizvoda utiče na stavove potrošača prema reklamiranju u sportu kao jedan od niza problema sa kojim se nije susrijetalo mnogo autora do sada (Bjelica, Popovic, \& Akpinar, 2014a; Bjelica, Popovic, \& Akpinar, 2015c; Bjelica, Popovic, \& Akpinar, 2016b; Bjelica, Popovic, \& Akpinar, 2017; Zoric, Masanovic, \& Gardasevic, 2017; Masanovic, Zoric, \& Gardasevic, 2018; Gardasevic, Zoric, \& Masanovic, 2018; Bajramović, Zorić, \& Mašanović, 2018; Gardašević, Bajramović, \& Mašanović, 2018; Zorić, Gardašević, \& Bajramović, 2018; Milovic, Corluka, \& Masanovic, 2018; Djurisic, Perovic, \& Masanovic, 2018; Kovacevic, Milosevic, \& Masanovic, 2018; Molnar, Masanovic, \& Bjelica, 2018; Masanovic, Georgiev, \& Sekulic, 2018; Stupar, Gardasevic, \& Masanovic, 2018), a to upravo i jeste cilj ove studije.

\section{Metod}

Populaciju u ovoj studiji su činili studenti Fakulteta sporta i fizičkog vaspitanja u Novom Sadu koji su u vrijeme anketiranja, imali boravište na teritoriji Srbije, dok je uzorak ispitanika organizovan putem kombinovanja ili raslojavanja, tako da su obrađena različita svojstva navedene populacije i različiti prostori na kojima je ona egzistirala.

Upitnici su distribuirani studentima osnovnih studija u štampanom i elektronskom obliku. Ukupno je prikupljeno 174 upit- nika, ali je 6 upitnika bilo isključeno iz analize, budući da nisu bili adekvatno popunjeni, tako da je u istraživanju učestvovalo, ukupno 168 ispitanika (Fakulteta sporta i fizičkog vaspitanja u Novom Sadu). Instrument istraživanja je predstavljao standardizovani upitnik (Popović, 2011) i sastojao se iz dva dijela, generalnih stavova prema reklamiranju u sportu i socio-demografskih karakteristika ispitanika kada je učestalost kupovine sportskih proizvoda tokom mjeseca u pitanju. Sistem promjenljivih u ovom upitniku je sadržao tri tvrdnje koje su ispitanici trebali da ocijene prema sedmo-stepenoj Likertovoj skali vrijednosti, kao i šest socio-demografskih karakteristika ispitanika (uopšte ne kupuju, manje od jednom mjesečno, 1-3 puta mjesečno, 4-6 puta mjesečno, 7-9 puta mjesečno, i više od 10 puta mjesečno). Popunjavanje upitnika nije trajalo, u prosjeku više od 10 minuta a ispitanici su $\mathrm{u}$ anketi učestvovali na dobrovoljnoj osnovi. Važno je naglasiti da je anketa bila anonimna i da su svi odgovori bili strogo poverljivi. Vrijedno je napomenuti i da su ispitanici, i pored svega navedenog imali mogućnost da u svakom momentu opozovu svoje učešće u anketi, ali se niko od njih nije na tako nešto odlučio.

Empirijski podaci su analizirani putem statističkog paketa za društvene nauke (SPSS 20.0), a kao prvi korak, bila je primijenjena deskriptivna statistika kojom su izračunati, prije svega frekvencija, zatim aritmetička sredina, standardna devijacija, kao i mjere asimetrije (Skewness) i spljoštenosti (Kurtosis) za svaku od tvrdnji. Budući da su se promjenljive u ovoj studiji nalazile na neparametrijskim skalama, radi detaljnijih analiza koje su slijedile, bilo je neophodno da se one, primjenom Blomovog postupka, transformišu u skale višeg reda. Zatim su primjenom multivarijatne analize varijanse (MANOVA), univarijatne analize varijanse (ANOVA) i LSD Post Hoc testa utvrđene razlike u generalnim stavovima ispitanika prema reklamiranju u sportu u odnosu kada je učestalost kupovine sportskih proizvoda tokom mjeseca u pitanju.

\section{Rezultati}

U prvoj tabeli su prikazani deskriptivni statističi podaci za sve tri tvrdnje koje su se odnosile na generalne stavove ispitanika prema reklamiranju u sportu. Prije svega, prikazana je aritmetička sredina koja oslikava pozitivne vrijednosti stavova kada su sve tri tvrdnje u pitanju, dok vrijednosti standardne devijacije pokazuju da elementi skupa, u prosjeku ne odstupaju značajno od aritmetičke sredine. Kada se govori o mjerama asimetrije (Skewness) i spljoštenosti (Kurtosis), negativne vrijednosti asimetrije kod svih promjenljivih pokazuju da je većina rezultata desno od srednje vrijednosti, među većim vrijednostima, dok pozitivne vrijednosti spljoštenosti kod jedne promjenljive (GSS2) pokazuju da je raspodjela šiljatija od normale tj. da ima više rezultata nagomilanih oko centra a negativne vrijednosti spljoštenosti kod dvije promjenljive (GSS1 i GSS3) pokazuju da je raspodjela pljosnatija od normalne tj. da ima više rezultata nagomilanih na repovima raspodjele.

Tabela 1. Generalni stavovi prema reklamiranju u sportu

\begin{tabular}{lcccccc}
\hline & \multirow{2}{*}{ Mean } & \multirow{2}{*}{ S.D. } & \multicolumn{2}{c}{ Skewness } & \multicolumn{2}{c}{ Kurtosis } \\
\cline { 4 - 7 } & & & Statistic & S.E. & Statistic & S.E. \\
\hline GSS1 & 5.09 & 1.634 & -.656 & .199 & -.069 & .396 \\
GSS2 & 5.36 & 1.587 & -.867 & .199 & .137 & .396 \\
GSS3 & 4.78 & 1.483 & -.243 & .199 & -.410 & .396 \\
\hline
\end{tabular}

Legenda: Mean - Aritmetička sredina; S.D. - Standardna devijacija; Skewness - Mjera asimetrije; Kurtosis Mjera spljoštenosti; Statistic - Statistička vrijednost; S.E. - Standardna greška; GSS1 - Moje opšte mišljenje je naklonjeno reklamiranju u sportu; GSS2 - Sveobuhvatno, smatram da je reklamiranje u sportu dobra stvar; GSS3 - Sveobuhvatno, da li ne volite ili volite reklamiranje u sportu 
U nastavku ove studije su prikazani komparativni statistički podaci generalnih stavova prema reklamiranju u sportu koji su dobijeni primjenom multivarijatne analize varijanse (MANOVA), univarijatne analize varijanse (ANOVA) i LSD Post Hoc testa, a u cilju utvrđivanja razlike u generalnim stavovima ispitanika prema reklamiranju u sportu u odnosu na učesta- lost kupovine sportskih proizvoda.

Inspekcijom druge tabele u kojoj su prikazani rezultati multivarijatne analize, jasno se uočava da u cijelom sistemu upoređivanih parametara ne postoji statistički značajna razlika u generalnim stavovima prema reklamiranju u sportu u odnosu na učestalost kupovine sportskih proizvoda $(\mathrm{p}=.064)$.

Tabela 2. Multivarijatna značajnost razlika u sistemu generalnih stavova prema reklamiranju u sportu kod ispitanika sa različitim navikama kada je kupovina sportskih proizvoda u pitanju

\begin{tabular}{|c|c|c|c|c|}
\hline & & $\mathbf{N}$ & Mean & S.D. \\
\hline \multirow[t]{7}{*}{ GSS1 } & Ne kupuju & 14 & 4.21 & 2.259 \\
\hline & $<1$ & 42 & 4.71 & 1.757 \\
\hline & $1-3$ & 63 & 5.44 & 1.412 \\
\hline & $4-6$ & 10 & 5.50 & 1.179 \\
\hline & $7-9$ & 7 & 5.00 & 1.155 \\
\hline & $>10$ & 12 & 5.33 & 1.614 \\
\hline & Ukupno & 148 & 5.09 & 1.634 \\
\hline \multirow[t]{7}{*}{ GSS2 } & Ne kupuju & 14 & 4.64 & 1.985 \\
\hline & $<1$ & 42 & 4.90 & 1.764 \\
\hline & $1-3$ & 63 & 5.54 & 1.342 \\
\hline & $4-6$ & 10 & 6.10 & 1.101 \\
\hline & $7-9$ & 7 & 5.57 & 1.272 \\
\hline & $>10$ & 12 & 6.17 & 1.586 \\
\hline & Ukupno & 148 & 5.36 & 1.587 \\
\hline \multirow[t]{7}{*}{ GSS3 } & Ne kupuju & 14 & 4.07 & 2.093 \\
\hline & $<1$ & 42 & 4.76 & 1.478 \\
\hline & $1-3$ & 63 & 4.79 & 1.346 \\
\hline & $4-6$ & 10 & 4.70 & 1.059 \\
\hline & $7-9$ & 7 & 5.14 & 1.215 \\
\hline & $>10$ & 12 & 5.50 & 1.679 \\
\hline & Ukupno & 148 & 4.78 & 1.483 \\
\hline
\end{tabular}

$F=1.628 ; p=.064$

Inspekcijom treće tabele u kojoj su prikazani rezultati univarijatne analize, jasno se uočava da je, ipak došlo do statistički značajnih razlika u generalnim stavovima prema reklamiranju u sportu u odnosu na učestalost kupovine sportskih proizvoda kod jedne od tri promjenljive dok kod dvije varijable navedena diskriminacija nije utvrđena.

Tabela 3. Univarijatna značajnost razlika u sistemu generalnih stavova prema reklamiranju u sportu kod ispitanika sa različitim navikama kada je kupovina sportskih proizvoda u pitanju

\begin{tabular}{ccc}
\hline & $\mathbf{F}$ & $\mathbf{p}$ \\
\hline GSS1 & 2.099 & .069 \\
GSS2 & 2.643 & .026 \\
GSS3 & 1.311 & .263 \\
\hline
\end{tabular}

Inspekcijom naredne tri tabele gdje su prikazani rezultati Post Hoc testa koji ukazuju na značajnost razlika između parova pojedinačnih entiteta sa različitim navikama kada je kupovina sportskih proizvoda u pitanju za svaku promjenlji- vu, po rezultatima koji su se pojavili na univarijatnom nivou, uočavamo statistički značajne razlike pojedinih parametara kod sve tri promjenljive.

Tabela 4. Utvrđivanje značajnih razlika u sistemu generalnih stavova prema reklamiranju u sportu primjenom Post Hoc testa između pojedinačnih entiteta sa različitim navikama kada je kupovina sportskih proizvoda u pitanju kod tvrdnje „moje opšte mišljenje je naklonjeno reklamiranju u sportu“

\begin{tabular}{cccccc}
\hline vs & Ne kupuju & $<\mathbf{1}$ & $\mathbf{1 - 3}$ & $\mathbf{4 - 6}$ & $\mathbf{7 - 9}$ \\
\hline$<1$ & .314 & & & & \\
$1-3$ & .010 & .024 & & & \\
$4-6$ & .055 & .166 & .919 & & \\
$7-9$ & .292 & .663 & .488 & .528 & \\
$>10$ & .078 & .241 & .826 & .809 & .663 \\
\hline
\end{tabular}


Rezultati Post Hok testa u četvrtoj tabeli ukazuju, da se kod prve tvrdnje „moje opšte mišljenje je naklonjeno reklamiranju u sportu“, pojavljuju razlike između ispitanika koji kupuju sportske proizvode 1-3 puta mjesečno i onih entiteta koji sportske proizvode ne kupuju, odnosno koji ih kupuju manje od jednom mjesečno. Može se uočiti najviše pozitivnih rezultata kod grupe koja kupuje sportske proizvode 4-6 puta mjesečno, dok se najmanje pozitivnih rezultata uočava kod grupe koja ne kupuje sportske proizvode.

Tabela 5. Utvrđivanje značajnih razlika u sistemu generalnih stavova prema reklamiranju u sportu primjenom Post Hoc testa između pojedinačnih entiteta sa različitim navikama kada je kupovina sportskih proizvoda u pitanju kod tvrdnje „sveobuhvatno, smatram da je reklamiranje u sportu dobra stvar" $^{\prime \prime}$

\begin{tabular}{cccccc}
\hline vs & Ne kupuju & $<\mathbf{1}$ & $\mathbf{1 - 3}$ & $\mathbf{4 - 6}$ & $\mathbf{7 - 9}$ \\
\hline$<1$ & .584 & & & & \\
$1-3$ & .051 & .041 & & & \\
$4-6$ & .024 & .029 & .288 & & \\
$7-9$ & .196 & .292 & .959 & .489 & \\
$>10$ & .013 & .014 & .200 & .920 & .419 \\
\hline
\end{tabular}

Rezultati Post Hok testa u petoj tabeli ukazuju, da kod druge tvrdnje „sveobuhvatno, smatram da je reklamiranje u sportu dobra stvar", pojavljuju razlike prije svega između ispitanika koji ne kupuju sportske proizvode i onih entiteta koji sportske proizvode kupuju 4-6 i preko 10 puta mjesečno. Razlike se takođe pojavljuju između onih ispitanika koji sportske proizvo- de kupuju manje od jednog puta mjesečno i ispitanika koji to čine 1-3, 4-6 i preko 10 puta mjesečno. Može se uočiti najviše pozitivnih rezultata kod tri grupe koje najviše kupuje sportske proizvode, dok se najmanje pozitivnih rezultata uočava kod grupe koja ne kupuje sportske proizvode.

Tabela 6. Utvrđivanje značajnih razlika u sistemu generalnih stavova prema reklamiranju u sportu primjenom Post Hoc testa između pojedinačnih entiteta sa različitim navikama kada je kupovina sportskih proizvoda u pitanju kod tvrdnje „sveobuhvatno, da li ne volite ili volite reklamiranje u sportu“

\begin{tabular}{cccccc}
\hline vs & Ne kupuju & $<\mathbf{1}$ & $\mathbf{1 - 3}$ & $\mathbf{4 - 6}$ & $\mathbf{7 - 9}$ \\
\hline$<1$ & .131 & & & & \\
$1-3$ & .100 & .914 & & & \\
$4-6$ & .305 & .905 & .852 & & \\
$7-9$ & .119 & .528 & .553 & .543 & \\
$>10$ & .015 & .128 & .131 & .207 & .611 \\
\hline
\end{tabular}

Rezultati Post Hok testa u šestoj tabeli, ukazuju da se kod treće tvrdnje „sveobuhvatno, da li ne volite ili volite reklamiranje u sportu“ pojavljuju razlike između ispitanika koji ne kupuju sportske proizvode i ispitanika koji kupuju sportske proizvode preko 10 puta mjesečno. Može se uočiti najviše pozitivnih rezultata kod dvije grupe koje najviše kupuje sportske proizvode, dok se najmanje pozitivnih rezultata uočava kod grupe koja ne kupuje sportske proizvode.

\section{Diskusija}

S obzirom da su rezultati pokazali da ispitanici imaju veoma pozitivan stav prema reklamiranju u sportu što potvrđuje visoka vrijednost aritmetičke sredine za sve tri promjenljive, kao i da skoro dvije trećine ispitanika imaju pozitivan stav prema reklamiranju u sportu što se ogleda u izrazito negativnim vrijednostima mjera asimetrije, trebalo bi naglasiti da su ovi rezultati usaglašeni sa rezultatima prethodnih istraživanja (Molnar, Lilić, Popović, Akpinar, \& Jakšić, 2011; Popović, Jakšić, Matić, Bjelica, \& Maksimović, 2014; Popović, Bjelica, Georgiev, \& Akpinar, 2011b; Popović, Matić, Milašinović, Jakšić, \& Bjelica, 2015d; Popović, Matić, Milašinović, Hadžić, Milošević, \& Bjelica, 2015e; Popović, Matić, Milašinović, Vujović, Milošević, \& Bjelica, 2015f; Popović, Jakšić, Matić, Bjelica, \& Maksimović, 2015g; Masanovic, Zoric, \& Gardasevic, 2017; Gardasevic, Zoric, \& Masanovic, 2017; Bjelica, Gardašević, \& Ćorluka, 2018; Ćorluka, Bjelica, \& Vukotić, 2018; Vukotić, Ćorluka, \& Mašanović, 2018), i da ne postoje značajne razlike koje bi trebalo pomenuti. Dobijeni rezultati, takođe jasno uka- zuju da ispitanici koji žive na različitim lokacijama, kao što su Sjedinjene države, Turska, Crna Gora, Srbija i Bosna i Hercegovina, imaju pozitivne stavove prema reklamiranju u sportu, dok je, ipak, poređenja radi, vrijedno navesti da, prema Mittal-u (Bjelica i sar., 2016a; Bjelica i sar., 2016c), različite studije ukazuju na negativne stavove kada je reklamiranje proizvoda $\mathrm{u}$ tradicionalnim industrijama u pitanju. Prema tome, više je nego evidentno da je primjena sporta u savremenoj poslovnoj komunikaciji uticala da se generalni stavovi potrošača značajno promijene kada je reklamiranje u pitanju, a prepoznavanje privlačnosti sporta je omogućilo poslovnim organizacijama da se približe sportskim potrošačima i na mnogo bezbolniji način utiču na njihovo ponašanje.

Utvrđivanjem razlike u generalnim stavovima ispitanika prema reklamiranju u sportu u odnosu na učestalost kupovine sportskih proizvoda, u ovoj studiji nijesu pronađene razlike u stavovima između ispitanika koji imaju različite navike kada je kupovina sportskih proizvoda u pitanju. Ove razlike su se pojavile kod jedne promjenljive na univarijantnom nivou. Kod sve tri poromjenjive „moje opšte mišljenje je naklonjeno reklamiranju u sportu“, „sveobuhvatno, smatram da je reklamiranje u sportu dobra stvar“ i „sveobuhvatno, da li ne volite ili volite reklamiranje u sportu" uočava se najmanje pozitivnih rezultata kod grupe koja ne kupuje sportske proizvode. $\mathrm{Na}$ osnovu statističkih analiza, utvrđeno je da se značajne razlike ne javljaju na multivarijatnom nivou, ali se javljaju kod jedne promjenljive na univarijatnom nivou značajnosti od $\mathrm{p}=.05$. Takođe, interesantno je istaći da se velika većina ispitanika 
identifikovala sa dva ponuđena entiteta, njih 105 (od 148), prije svega sa potrošačima koji sportske proizvode kupuju manje od jedanput mjesečno i sa potrošačima koji sportske proizvode kupuju jedanput do tri puta mjesečno.

Buduća istraživanja bi trebalo usmjeriti na veći broj ispitanika, budući da se značajan broj ispitanika grupiše u kategoriju sa manjim brojem kupovine sportskih proizvoda tokom mjeseca, posebno iz razloga što se očekuje da bi neke razlike mogle biti interesantne i korisne kako za teoriju tako i za praksu.

\section{Acknowledgements}

There are no acknowledgements.

\section{Conflict of Interest}

The authors declare that there are no conflict of interest.

Received: 16 April 2018| Accepted: 01 June 2018| Published: 13 July 2018

\section{References}

Bajramović, I., Zorić, G., \& Mašanović, B. (2018). Attitudes of Consumers from the Sarajevo Canton in Bosnia and Herzegovina toward Advertising through Sport among the Frequency of Watching Sports Events. Journal of Anthropology of Sport and Physical Education, 2(2), 43-7.

Bjelica, D., \& Popović, S. (2015a). Evolucija reklamiranja sa posebnim osvrtom na reklamiranje u sportu. Sport Mont, 13(43,44,45), 35-41.

Bjelica, D., \& Popović, S. (2015b). Evolution of Advertising with a Specific Retrospection at Sport Advertising. In Book of Abstracts of the 12th International Scientific Conference on Transformation Process in Sport "Sport Performance" (60-61), Podgorica: Montenegrin Sports Academy.

Bjelica, D., Gardašević, J., \& Ćorluka, M. (2018). Attitudes of Consumers from the Mostrar Canton in Bosnia and Herzegovina toward Advertising through Sport among the Question how often Consumers purchase Sporting Goods. Journal of Anthropology of Sport and Physical Education, 2(2), 3-7.

Bjelica, D., Gardašević, J., Vasiljević, I., \& Popović, S. (2016a). Ethical Dilemmas of Sport Advertising. Sport Mont, 14(3), 41-3.

Bjelica, D., Gardašević, J., Vasiljević, I., \& Popović, S. (2016c). Ethical dilemmas of sport advertising. In Book of Abstracts of the 13th International Scientific Conference on Transformation Process in Sport "Sport Performance" (41), Podgorica: Montenegrin Sports Academy.

Bjelica, D., i Popović, S. (2011). Stavovi potrošača prema reklamiranju u sportu u odnosu na učestalost posmatranja sportskih događaja. Sportske nauke i zdravlje, 1(2), 114-9.

Bjelica, D., Popovic, S., \& Akpinar, S. (2015c). Book of Abstracts of the 12th International Scientific Conference on Transformation Process in Sport "Sport Performance". Podgorica: Montenegrin Sports Academy.

Bjelica, D., Popović, S., \& Akpinar, S. (2014a). Book of Abstracts of the 11th International Scientific Conference on Transformation Process in Sport "Sport Performance". Podgorica: Montenegrin Sports Academy.

Bjelica, D., Popović, S., \& Akpinar, S. (2016b). Book of Abstracts of the 13th International Scientific Conference on Transformation Process in Sport "Sport Performance". Podgorica: Montenegrin Sports Academy.

Bjelica, D., Popović, S., \& Akpinar, S. (2017). Book of Abstracts of the 14th International Scientific Conference on Transformation Process in Sport "Sport Performance". Podgorica: Montenegrin Sports Academy.

Bjelica, D., Popović, S., Jakšić, D., Hadžić, R., \& Akpinar, S. (2014b). How Does Advertising through Sport Work? Evidence from Turkey. In Proceedings book of the 7th International Scientific Conference on Kinesiology „Fundamental and Applied Kinesiology - Steps Forward "(477). Opatija: University of Zegreb, Faculty of Kinesiology.

Corluka, M., Bjelica, D., \& Vukotić, M. (2018). Attitudes of Consumers from the Mostar Canton in Bosnia and Herzegovina toward Advertising through Sport among the Question how Often they Participate in Sports Activities. Journal of Anthropology of Sport and Physical Education, 2(2), 9-13.

Djurisic, V., Perovic, D., \& Masanovic, B. (2018). Attitudes of consumers from Podgorica toward advertising through sport among the question how often consumers purchase sporting goods. Journal of Anthropology of Sport and Physical Education, 2(2), 55-60. doi: 10.26773/jaspe. 180410

Gardašević, J., Bajramović, I., \& Mašanović, B. (2018). Attitudes of Consumers from the Sarajevo Canton in Bosnia and Herzegovina toward Advertising through Sport among the Question how Often they Participate in Sports Activities. Journal of Anthropology of Sport and Physical Education, 2(2), 37-41.

Gardašević, J., Zorić, G., \& Mašanović, B. (2017). Attitudes of Turkish consu mers toward advertising through sport among the question how often they participate in sports activities. Journal of Anthropology of Sport and Physical Education, 1(1), 23-7.

Gardašević, J., Zorić, G., \& Mašanović, B. (2018). Attitudes of Montenegrin consumers toward advertising through sport among the question how often they participate in sports activities. Journal of Anthropology of Sport and Physical Education, 2(1), 15-9.

Klačar, M. i Popović, S. (2010). Reklamiranje u sportu kao efektivno sredstvo savremene komunikacije. Teme, 4, 1219-30.

Kovacevic, D., Milosevic, Z., \& Masanovic, B. (2018). Attitudes of consumers from Podgorica toward advertising through sport among the question how often they participate in sports activities. Journal of Anthropology of Sport and Physical Education, 2(2), 61-5. doi: 10.26773/jaspe.180411

Masanovic, B., Georgiev, G., \& Sekulic, N. (2018). Attitudes of Consumers from Subotica toward Advertising through Sport among the Question how often Consumers purchase Sporting Goods. Journal of Anthropology of Sport and Physical Education, 2(3).

Mašanovic, B., Zorić, G., \& Gardašević, J. (2018). Attitudes of Montenegrin consumers toward advertising through sport among the frequency of watching sports events. Journal of Anthropology of Sport and Physical Education, 2(1), 9-13.

Mašanovic, B., Zorić, G., \& Gardašević, J. (2017). Attitudes of Turkish consumers toward advertising through sport among the frequency of watching sports events. Journal of Anthropology of Sport and Physical Education, 1(1), 3-7.

Milovic, N., Corluka, M., \& Masanovic, B. (2018). Attitudes of consumers from Podgorica toward advertising through sport among the frequency of watching sports events. Journal of Anthropology of Sport and Physical Education, 2(2), 71-6. doi: 10.26773/jaspe.180413

Molnar, S., Lilić, Lj., Popović, S., Akpinar, S., \& Jakšić, D. (2011). Attitudes of various demographic groups toward advertising through sport at METU. Facta Universitatis, Series: Physical Education and Sport, 9(3), 255-63.

Molnar, S., Masanovic, B., \& Bjelica, D. (2018). Attitudes of Consumers from University of Novi Sad toward Advertising through Sport among the Frequency of Watching Sports Events. Journal of Anthropology of Sport and Physical Education, 2(3).

Muratović, A., Bjelica, D., \& Popović, S. (2014). Examining beliefs and attitudes toward advertising through sport among montenegrin consumers. Facta Universitatis, Series: Physical Education and Sport, 12(2), 95-104.

Popovic, S. (2015). Sport Nowadays (In Montenegrin). In D. Bjelica (Ed.), Advertising Role of Sponsorship in Modern Sport (pp. 111-6). Podgorica: Montenegrin Sports Academy.

Popović, S. \& Milašinović, R. (2016). Model of Advertising Communication in Sport. Sport Mont, 14(1), 33-8.

Popović, S. (2011). Reklamiranje u sportu kao efektivno sredstvo savremene poslovne komunikacije. Neobjavljena doktoska disertacija, Novi Sad: Univerzitet u Novom Sadu.

Popović, S. (2011b). Stavovi potrošača prema reklamiranju u sportu u odnosu na učestalost kupovine sportskih proizvoda. Sport Mont, 9(28,29,30), $140-7$.

Popović, S., Bjelica, D., Georgiev, G., \& Akpinar, S. (2011b). Comparison of attitudes toward advertising through sport between Montenegrin and Turkish stakeholders. In Proceedings book of the 6th International Scientific Conference on Kinesiology "Integrative Power of Kinesiology" (612). Opatija: University of Zegreb, Faculty of Kinesiology.

Popović, S., Bjelica, D., Jakšić, D, \& Georgiev, G. (2013). How does Advertising Through Sport Work? Evidence from Montenegro. In Book of Abstracts of the $18^{\text {th }}$ Annual Congress of the European College of Sport Science (444-5), Barcelona: National Institute of Physical Education of Catalonia.

Popović, S., Jakšić, D., Matić, R., Bjelica, D., \& Maksimović, N. (2014). Examining Beliefs and Attitudes toward Advertising through Sport among Serbian Consumers. In Book of abstracts of International conference "Economics and Management of Sports 2014" (pp. 11-2). Brno: Faculty of Sports Studies.

Popović, S., Jakšić, D., Matić, R., Bjelica, D., \& Maksimović, N. (2015g). Examining Beliefs and Attitudes toward Advertising through Sport among Serbian Consumers. Studia Sportiva, 9(1), 225-31.

Popović, S., Matić, R., Milašinović, R., Hadžić, R., Milošević, Z., \& Bjelica, D. (2015b). Stavovi srbijanskih potrošača prema reklamiranju u sportu u odnosu na učestalost kupovine sportskih proizvoda. Sport Mont, 13(43,44,45), 262-9.

Popović, S., Matić, R., Milašinović, R., Hadžić, R., Milošević, Z., \& Bjelica, D. (2015e). Attitudes of Serbian Consumers toward Advertising through Sport among the Question How Often Consumers Purchase Sporting Goods. InBook of Abstracts of the 12th International Scientific Conference on Transformation Process in Sport "Sport Performance" (59-60), Podgorica: Montenegrin Sports Academy.

Popović, S., Matić, R., Milašinović, R., Jakšić, D., \& Bjelica, D. (2015a). Stavovi 
srbijanskih potrošača prema reklamiranju u sportu u odnosu na učestalost bavljenja sportskim aktivnostima. Sport Mont, 13(43,44,45), 50-6.

Popović, S., Matić, R., Milašinović, R., Jakšić, D., \& Bjelica, D. (2015d). Attitudes of Serbian Consumers toward Advertising through Sport among the Question How Often They Participate in Sports Activities. In Book of Abstracts of the 12th International Scientific Conference on Transformation Process in Sport "Sport Performance" (58-9), Podgorica: Montenegrin Sports Academy.

Popović, S., Matić, R., Milašinović, R., Vujović, D., Milošević, Z., \& Bjelica, D. (2015c). Stavovi srbijanskih potrošača prema reklamiranju u sportu u odnosu na učestalost posmatranja sportskih događaja. Sport Mont 13(43,44,45), 270-6

Popović, S., Matić, R., Milašinović, R., Vujović, D., Milošević, Z., \& Bjelica, D. (2015f). Attitudes of Serbian Consumers toward Advertising through Sport among the Frequency of Watching Sports Events. In Book of Abstracts of the 12th International Scientific Conference on Transformation Process in Sport "Sport Performance" (60), Podgorica: Montenegrin Sports Academy.

Popović, S., Molnar, S., i Radovanović, D. (2011a). Stavovi potrošača prema reklamiranju u sportu u odnosu na učestalost bavljenja sportskim aktivnostima. Sport Mont, 9(28,29,30), 148-55.
Stupar, D., Gardasevic, J., \& Masanovic, B. (2018). Attitudes of Consumers from Educons University toward Advertising through Sport among the Frequency of Watching Sports Events. Journal of Anthropology of Sport and Physical Education, 2(3).

Vukotić, M., Ćorluka, M., \& Mašanović, B. (2018). Attitudes of Consumers from the Mostar Canton in Bosnia and Herzegovina toward Advertising through Sport among the Frequency of Watching Sports Events. Journal of Anthropology of Sport and Physical Education, 2(2), 19-23.

Zorić, G., Gardašević, J., \& Bajramović, I. (2018). Attitudes of Consumers from the Sarajevo Canton in Bosnia and Herzegovina toward Advertising through Sport among the Question how often Consumers purchase Sporting Goods. Journal of Anthropology of Sport and Physical Education, 2(2), 25-9.

Zorić, G., Mašanović, B., \& Gardašević, J. (2017). Attitudes of Turskish consumers toward advertising through sport among the question how often consumers purchase sporting goods. Journal of Anthropology of Sport and Physical Education, 1(1), 17-21. doi: 10.26773/jaspe.171003

Zorić, G., Mašanović, B., \& Gardašević, J. (2018). Attitudes of Montenegrin consumers toward advertising through sport among the question how often consumers purchase sporting goods. Journal of Anthropology of Sport and Physical Education, 2(1), 21-5. 